\title{
Selective cerebral perfusion for thoracic aortic surgery: Association with neurocognitive outcome
}

\author{
Suzan Uysal, PhD, Hung-Mo Lin, PhD, Gregory W. Fischer, MD, Gabriele Di Luozzo, MD, and \\ David L. Reich, MD
}

\begin{abstract}
Objectives: Optimal brain protection for aortic arch surgery remains unclear. This prospective study examined neurocognitive outcomes in cardiac and thoracic aortic surgical patients, including a small cohort who underwent selective cerebral perfusion.
\end{abstract}

\begin{abstract}
Methods: Fifty-seven adult cardiac and thoracic aortic surgical patients underwent preoperative and postoperative neurocognitive testing. Patients were divided into 3 groups. Group 1 patients underwent procedures with cardiopulmonary bypass alone $(\mathrm{n}=24)$, group 2 patients with cardiopulmonary bypass and hypothermic circulatory arrest $(\mathrm{n}=23)$, and group 3 patients with cardiopulmonary bypass, hypothermic circulatory arrest, and anterograde selective cerebral perfusion $(n=10)$. Changes in 14 neurocognitive test scores and 6 neurocognitive domain scores (Attention, Speed, Language, Memory, Executive Function, and Motor Function) were evaluated.
\end{abstract}

Results: Multiple regression analyses examining the relationships of cardiopulmonary bypass time, hypothermic circulatory arrest time, and selective cerebral perfusion time with change in cognitive test performance revealed that selective cerebral perfusion time (range, 39-83 minutes) was a significant predictor of decline in performance on memory and language tests. Hypothermic circulatory arrest (range, 14-40 minutes) and cardiopulmonary bypass (range, 70-369 minutes) times were unrelated to decline.

Conclusions: Complex thoracic aortic repairs requiring prolonged selective cerebral perfusion were associated with decline in neurocognitive function. It is unclear whether the complexity of the repair necessitating prolonged selective cerebral perfusion or the perfusion technique itself contributed to neurocognitive decline. Prospective multicenter neurocognitive evaluations are necessary to assess the relative merits of current brain protection strategies in thoracic aortic surgery. (J Thorac Cardiovasc Surg 2012;143:1205-12)

The technique of thoracic aortic surgery was revolutionized in 1975, when Griepp and colleagues ${ }^{1}$ introduced hypothermic circulatory arrest (HCA) to allow sufficient time to conduct surgical repairs in a bloodless field with acceptable to excellent neurologic outcomes. As it came to be recognized that the "safe" duration of HCA is limited, adjunct techniques aimed at providing blood flow and metabolic support to the brain were introduced to extend the time available for complex aortic reconstructions. Retrograde cerebral perfusion (RCP) is commonly used as a cerebral perfusion adjunct jointly with HCA. Its efficacy for providing metabolic support and improving neurologic outcomes remains controversial, however, and some data suggest that RCP has deleterious effects. ${ }^{2,3}$ For this reason, and as a result of surgical innovation, antegrade selective cerebral perfusion (SCP) is now used in many centers.

\footnotetext{
From the Departments of Anesthesiology and Cardiothoracic Surgery, Mount Sinai School of Medicine, New York, NY.

Disclosures: Authors have nothing to disclose with regard to commercial support. Received for publication April 13, 2011; revisions received Nov 18, 2011; accepted for publication Jan 4, 2012; available ahead of print Feb 3, 2012.

Address for reprints: Suzan Uysal, PhD, Department of Anesthesiology, Box 1010,

Mount Sinai School of Medicine, One Gustave L. Levy Place, New York, NY

10029-6574 (E-mail: suzan.uysal@mountsinai.org).

$0022-5223 / \$ 36.00$

Copyright (c) 2012 by The American Association for Thoracic Surgery

doi:10.1016/j.jtcvs.2012.01.012
}

It is difficult to evaluate the relative neuroprotective efficacies of these techniques, because the patient groups differ with respect to multiple variables that potentially influence outcome. The potentially confounding variables include the following: preoperative factors, such as cognitive and neurologic status, overall health, and atherosclerotic disease; operative factors, such as emergency versus elective surgery and surgical complexity; and postoperative factors, such as neurologic morbidity (stroke and transient nonfocal neurologic symptoms), nonneurologic morbidity, and mortality. Moreover, there is marked variability among centers and across time with respect to HCA, RCP, and SCP protocols. Thus the existing literature consists mainly of retrospective reports of gross neurologic outcomes from single-center cohorts. The issue of the optimal methods of brain protection during thoracic aortic surgery remains controversial. ${ }^{4-7}$

There have been few neurocognitive outcome studies examining the efficacy of intraoperative neuroprotection for thoracic aortic surgery. We found that preoperative to postoperative changes in memory and fine motor function were worse in patients with HCA times of at least 25 minutes, relative to patients with shorter periods of HCA or with cardiopulmonary bypass $(\mathrm{CPB})$ without $\mathrm{HCA}{ }^{8}$ Our subsequent experience with RCP was associated with worse neurocognitive outcome than was HCA alone, consistent with the findings of other studies. ${ }^{9-11}$ In more recent years, we 


$$
\begin{aligned}
& \text { Abbreviations and Acronyms } \\
& \begin{aligned}
\text { CABG } & =\text { coronary artery bypass grafting } \\
\text { CPB } & =\text { cardiopulmonary bypass } \\
\text { FTT } & =\text { Finger Tapping Test } \\
\text { GPB } & =\text { Grooved Pegboard Test } \\
\text { HCA } & =\text { hypothermic circulatory arrest } \\
\text { HVLT-R } & =\text { Hopkins Verbal Learning Test-Revised } \\
\text { RCP } & =\text { retrograde cerebral perfusion } \\
\text { SCP } & =\text { selective cerebral perfusion } \\
\text { TMT-A } & =\text { Trail Making Test A } \\
\text { TMT-B } & =\text { Trail Making Test B }
\end{aligned}
\end{aligned}
$$

have used SCP as the primary adjunct perfusion technique. In this prospective study, we sought to evaluate further the roles of HCA and SCP as predictors of preoperative to postoperative cognitive decline.

\section{MATERIALS AND METHODS Patients}

The study protocol was approved by the institutional review board. Adult patients undergoing nonemergency cardiac or proximal aortic surgery with $\mathrm{CPB}$ or thoracic aortic surgery with HCA between February 28 , 2002, and June 16, 2008, were recruited into the study after providing informed consent. Patients were divided into 3 groups. Group 1 patients underwent coronary artery and cardiac valve procedures with CPB. Group 2 patients underwent thoracic aortic procedures with $\mathrm{CPB}$ and at least 1 period of HCA. Finally, group 3 patients underwent thoracic aortic procedures with $\mathrm{CPB}, \mathrm{HCA}$, and at least 1 period of SCP.

\section{Anesthesia and Monitoring}

General anesthesia was induced with a hypnotic agent (etomidate, propofol) and supplemented with an opioid analgesic (fentanyl, sufentanil) and a benzodiazepine (midazolam hydrochloride). Maintenance consisted of isoflurane (0.6-1.5\% end-tidal concentration), fentanyl, neuromuscular blockers, and midazolam. All patients had mechanical ventilation with a fraction of inspired oxygen of 1.0 to maintain the $\mathrm{PaCO}_{2}$ at 35 to 45 $\mathrm{mm} \mathrm{Hg}$.

The following monitors were placed: a radial arterial catheter, a pulmonary arterial catheter, and temperature monitoring of the urinary bladder catheter and the esophagus or nasopharynx. For HCA, a 20-gauge jugular bulb catheter for intermittent sampling of jugular venous blood was placed and confirmed by baseline jugular bulb venous saturation measurement. Patients enrolled during the later years of the series underwent nearinfrared spectroscopic monitoring of transcranial cerebral oxygenation and bispectral index monitoring.

\section{Surgical and Perfusion Techniques}

All patients underwent midline sternotomy. All patients undergoing HCA had direct right axillary cannulation or end-to-side graft anastomosis for CPB arterial inflow. Antegrade crystalloid or blood cardioplegia was used every 20 to 30 minutes, either through an aortic root cannula or directly into the coronary ostia, and the left ventricle was vented. In patients who did not undergo HCA, operations were performed with standard $\mathrm{CPB}$ at mild to moderate hypothermia $\left(28^{\circ} \mathrm{C}-35^{\circ} \mathrm{C}\right)$.

The techniques of HCA were consistent throughout the duration of the study and have been described in detail previously. ${ }^{12}$ Briefly, cooling during $\mathrm{CPB}$ was performed until a core temperature of $12^{\circ} \mathrm{C}$ to $15^{\circ} \mathrm{C}$, as measured by a urinary bladder thermistor, was achieved. Alpha-stat $\mathrm{pH}$ management was used, and cooling times of 45 minutes or longer were generally required. Cooling was continued until jugular venous saturation exceeded $95 \%$ in most cases and $90 \%$ in all. The head was packed in ice before commencement of HCA for intervals expected to exceed 20 minutes. All patients undergoing HCA were administered $30 \mathrm{mg} / \mathrm{kg}$ of methylprednisolone before CPB. In patients with combined HCA and SCP times exceeding 30 minutes, tapering doses of glucocorticoids were continued in the intensive care unit for 48 hours.

In repairs involving the transverse aortic arch, the brachiocephalic vessels were anastomosed to a trifurcated graft during a brief period of HCA. ${ }^{13}$ The proximal end of the trifurcated graft was then clamped, and SCP was instituted through the right axillary cannula. We used alpha-stat management, perfusate temperatures between $15^{\circ} \mathrm{C}$ and $20^{\circ} \mathrm{C}$, hematocrit of $20 \%$ to $30 \%$, and flows of approximately $10 \mathrm{~mL} /(\mathrm{kg} / \mathrm{min})$ titrated to maintain a mean arterial pressure of 40 to $60 \mathrm{~mm} \mathrm{Hg}$. Adequacy of cerebral oxygenation was confirmed by near-infrared spectroscopy and cerebral oximetry in the later years of the series, although no specific criteria were set.

On completion of the HCA and SCP portions of the procedures, gradual systemic rewarming was carried out by means of $\mathrm{CPB}$, limiting the gradient between perfusate and urinary bladder temperature to less than $10^{\circ} \mathrm{C}$, with a maximum perfusate temperature of $37^{\circ} \mathrm{C}$. Rewarming was discontinued once an esophageal temperature of $35^{\circ} \mathrm{C}$ to $37^{\circ} \mathrm{C}$ and a urinary bladder temperature of $32^{\circ} \mathrm{C}$ to $35^{\circ} \mathrm{C}$ had been achieved.

$\mathrm{CPB}$ time was defined as the cumulative time on full-body CPB, exclusive of HCA or SCP. HCA time was defined as the cumulative time on fullbody circulatory arrest, exclusive of SCP. Brain perfusion time was defined as the cumulative time on full-body $\mathrm{CPB}$ and $\mathrm{SCP}$, which was equivalent to CPB time for groups 1 and 2. CPB onset-to-offset time was defined as the cumulative time from initiation of $\mathrm{CPB}$ to weaning from $\mathrm{CPB}$, regardless of whether HCA or SCP was used within that interval. Surgical time was defined as the time from incision to closure.

\section{Neurocognitive Testing}

Neurocognitive testing was performed preoperatively at preadmission testing and postoperatively when patients returned to the hospital for surgical follow-up visit. The neurocognitive test battery consisted of 8 tests yielding 14 test scores that assessed 6 domains of function, as summarized in Table 1. The tests used were as follows: Wechsler Memory Scale III Digit Span subtest (Psychological Corporation, New York, NY); Trail Making Test (TMT-A and TMT-B; Neuropsychology Press, Tuscon, Ariz); Symbol Digit Modalities Test, oral version (Western Psychological Services, Los Angeles, Calif); Boston Naming Test-15 item version ${ }^{14}$; Hopkins Verbal Learning Test-Revised (HVLT-R; Psychological Assessment Resources, Inc, Odessa Fla); Stroop Color and Word Test (Stoelting Co, Wood Dale, Ill); Finger Tapping Test (FTT; Psychological Assessment Resources); and Grooved Pegboard Test (GPB; Psychological Assessment Resources). Alternate forms of the HVLT-R and Boston Naming Test-15 item version were administered across the preoperative and postoperative test sessions in a counterbalanced fashion. Only the dominant hand was tested with the FTT and GPB.

\section{Statistical Methods}

The initial step in analyzing the neurocognitive test data was to convert raw test scores to $z$ scores. The normalized $z$ score reflects where an observed raw data point stands in relation to a reference group, allowing for comparison across tests. For the purpose of standardization, we chose the group of patients who underwent preoperative neurocognitive testing and subsequent surgical procedures with CPB only as the reference group. The difference between preoperative and postoperative $z$ scores was then computed for each test measure and each patient. Logarithmic transformation was performed on the time-related tests (TMT-A, TMT-B, and GPB) to improve normality of the data. Because higher scores reflect poorer 
TABLE 1. Neurocognitive battery assessing 6 domains of function

\begin{tabular}{ll}
\hline \multicolumn{1}{c}{ Test } & \multicolumn{1}{c}{ Test score } \\
\hline $\begin{array}{l}\text { Attention } \\
\text { Wechsler Memory Scale III } \\
\text { Digit Span subtest }\end{array}$ & Digits Forward \\
& $\begin{array}{l}\text { Digits Backward } \\
\text { Digit Span }\end{array}$ \\
$\begin{array}{ll}\text { Processing speed } \\
\text { The Trail Making Test (TMT) }\end{array}$ & $\begin{array}{l}\text { Trail Making Test, Part A (TMT-A) } \\
\text { Trail Making Test, Part B (TMT-B) }\end{array}$ \\
The Symbol Digit Modalities & SDMT \\
Test, oral version & \\
Language & \\
Boston Naming Test-15 & BNT-15 \\
item version & \\
Memory & \\
Hopkins Verbal Learning & HVLT-R Total Recall \\
Test-Revised (HVLT-R) & \\
& HVLT-R Delayed Recall \\
& HVLT-R Retention \\
Executive function & HVLT-R Recognition \\
Stroop Color and Word Test & Stroop Interference (Stroop) \\
Motor function & FTT \\
Finger Tapping Test & GPB \\
Grooved Pegboard Test & \\
\hline
\end{tabular}

performance for these tests, postoperative scores were subtracted from preoperative scores to ensure that negative difference scores would reflect a decline in function for all measures.

To reduce the number of statistical analyses and decrease the risk of type I error, we classified the 14 test scores into 6 domains: Attention, Processing Speed, Language, Memory, Executive Function, and Motor Function. Cluster analysis was used to confirm our conceptual grouping of the neurocognitive tests by the variable cluster analysis (VARCLUS) procedure in the SAS 9.1.3 statistical analysis software package (SAS Institute, Inc, Cary, NC). This procedure uses iterative splitting (until a stopping criterion is met) and factor analysis methods to divide a set of variables into nonoverlapping subgroups. Because the VARCLUS procedure used for variable cluster analysis removes subjects with incomplete data, and the HVLT-R Retention, FTT, and GPB variables had greater than $15 \%$ missing data, we excluded those variables from the cluster analysis. Complete preoperative neurocognitive test data were available for 83 patients on 11 of the 14 neurocognitive test scores. After controlling for age and education, cluster analysis yielded 5 clusters: Attention (Digits Forward, Digits Backward, Digit Span), Processing Speed (TMT-A, TMT-B, and Symbol Digit Modalities Test, oral version), Language (Boston Naming Test-15 item version), Memory (HVLT-R Total Recall, HVLT-R Delayed Recall, and HVLT-R Recognition), and Executive Function (Stroop). The proportion of variation explained by these five clusters was $78 \%$. We then assigned the HVLT-R Retention variable to the Memory domain and the FTT and GPB variables to the Motor Function domain. Finally, a composite score for each domain for each patient was created by averaging the difference in $z$ scores for the variables in the cluster.

Statistical analyses were carried out using the SAS statistical software package (version 9.1.3). For group comparisons, $\chi^{2}$ tests were used for binary categoric variables, Students $t$ tests or analysis of variance (allowing heterogeneous variance across the groups) were used for normally distributed continuous variables, and nonparametric Kruskal-Wallis tests were used for nonnormally distributed continuous variables.
Multiple linear regression analysis was used to model the associations between the 3 types of perfusion and arrest times (CPB, HCA, and SCP) and each of the neurocognitive test scores and domain scores, independent of group assignment. The analyses assumed that the practice effects of the tests were independent of the perfusion and arrest times. The models adjusted for preoperative neurocognitive scores and number of days since surgery. Because of the small sample size, we chose not to adjust for age and education level, assuming that the effects of these variables should be reflected in the baseline test scores. The models also adjusted for use of HCA or SCP as binary variables (present or absent). To explore the possibility of nonlinear relationships between CPB, HCA, and SCP times and postoperative neurocognitive performance, a quadratic polynomial term for $\mathrm{CPB}, \mathrm{HCA}$, and $\mathrm{SCP}$ times was tested for statistical significance. Two-way interactions among use of HCA or SCP and perfusion and arrest times were also tested.

To examine further the association between SCP time and neurocognitive decline, we performed propensity score analysis that matched 10 patients from the HCA group with 10 from the SCP group. We used the sampling with replacement technique to test the effects of SCP when the matched pairs had similar brain perfusion time and HCA time. From the sample of SCP group and HCA group subjects, a logistic regression was performed to predict the probability (propensity score) of SCP group membership by using age, education, brain perfusion time, and HCA time as predictors. The balance of the covariates (age, education, time of postoperative testing, baseline neurocognitive domain $z$ scores, brain perfusion time, and HCA time) between the resulting matched pairs were compared with $t$ tests, and all differences were nonsignificant. In the next step, we repeated the multiple regression analysis for SCP time, adjusting for SCP use, preoperative neurocognitive scores, and time of postoperative testing.

\section{RESULTS}

\section{Demographic Characteristics}

A total of 178 cardiac and thoracic aortic surgical patients underwent preoperative neuropsychologic testing: 88 $(49.4 \%)$ in group $1,61(34.3 \%)$ in group 2, and 29 $(16.3 \%)$ in group 3 . Fifty-seven of those patients $(32 \%)$ underwent postoperative neuropsychologic testing at the outpatient follow-up visit: $24(42.1 \%)$ in group 1, $23(40.4 \%)$ in group 2, and $10(17.5 \%)$ in group 3 . The return rates for postoperative neuropsychologic testing were $27 \%, 38 \%$, and $34 \%$ for groups 1,2 , and 3 , respectively $(P=.34)$. Postoperative testing occurred 15 to 233 days (median, 44 days) after surgery.

Of the 121 patients unavailable for follow-up, $3(0,2$, and 1 for groups 1 through 3 , respectively) died before hospital discharge, $2(0,1$, and 1$)$ had strokes, and $9(4,3$, and 2$)$ had medical complications necessitating their discharge to other facilities (rehabilitation, acute care, or skilled nursing facilities). Relative to patients who were unavailable for follow-up $(n=121)$, patients who underwent postoperative neuropsychologic testing $(\mathrm{n}=57)$ were on average 5 years younger (58 years vs 63 years; $P=.03$ ). They did not differ with respect to level of education $(P=.97)$ or postsurgical hospital stay $(P=.30)$.

The surgical procedures of patients in group $1(\mathrm{n}=24)$ were single valve repairs $(\mathrm{n}=11)$, multiple valve repairs $(\mathrm{n}=6)$, coronary artery bypass grafting $(\mathrm{CABG} ; \mathrm{n}=2)$, $\mathrm{CABG}$ and valve repair $(\mathrm{n}=2)$, and ascending aortic 
repairs $(n=3)$. The surgical procedures of patients in group $2(\mathrm{n}=23)$ were ascending aortic repairs $(\mathrm{n}=13)$, ascending aortic repairs with $\mathrm{CABG}(\mathrm{n}=5)$, ascending aortic repairs with mitral valve repair $(\mathrm{n}=1)$, ascending aortic repairs with CABG and aortic valve repair $(n=2)$, hemiarch replacement with aortic valve repair $(n=1)$, and aortic arch repair $(n=1)$. The surgical procedures of patients in group $3(n=10)$ were aortic arch replacement $(n=8)$, ascending aortic repair $(\mathrm{n}=1)$, and thoracoabdominal aortic repair $(\mathrm{n}=1)$.

\section{Group Comparisons}

Table 2 presents the characteristics of patients who underwent both preoperative and postoperative neurocognitive testing. The treatment groups were similar with respect to age and education. Group 1 had significantly more men than did group 3. The groups differed with respect to hospital stay and time to postoperative testing, with group 1 having significantly shorter intervals from surgery to hospital discharge and from surgery to postoperative testing. Duration and complexity of surgery, as assessed by surgical duration and CPB onset-to-offset time, was significantly greater in groups 2 and 3 relative to group 1. Group 3 underwent significantly longer intervals of HCA than did group 2. Total brain perfusion time was not significantly different between groups 2 and 3 .

Table 3 summarizes the raw preoperative and postoperative test scores and $z$ score differences. Overall, the 3 groups differed on 3 of the 14 difference scores (TMT-B, HVLT-R
Total Recall, and FTT), with group 3 performing significantly worse than group 2 .

\section{Relationships of Perfusion and Arrest Times to Neurocognitive Outcomes}

Table 4 presents the results of multiple regression analyses examining the relationships of CPB, HCA, and SCP times (independent of group assignment) with the 6 neurocognitive domain scores after adjustment for potential confounders. The results indicate that SCP time (range, 39-83 minutes) was a significant predictor of decline in the domains of Memory and Language. HCA time (range, 14-40 minutes) was not a significant predictor of decline in any domain, and there was no significant interaction between HCA time and SCP use. CPB time (range, 70-369 minutes) was not a significant predictor of decline in any domain, and there was no significant interaction between CPB time and HCA use or SCP use. As a sensitivity analysis, the propensity score analysis (Table 4) that used 10 matched pairs from the SCP and HCA groups confirmed a significant association between SCP time and decline in language $(P=.002)$. The effect of SCP on the memory decline trended in the same direction as that seen from the traditional regression analysis, with a $P$ value of .063 (Table 4). The lack of statistical significance could be the result of low study power, with only 10 SCP matched pairs.

Figure 1 presents the relationships between SCP time and the neurocognitive domain scores. The correlations between SCP time and Memory and Language domain scores

TABLE 2. Group characteristics

\begin{tabular}{|c|c|c|c|c|}
\hline Variable & $\begin{array}{l}\text { Group 1, CPB } \\
\text { only }(N=24)\end{array}$ & $\begin{array}{c}\text { Group 2, CPB }+ \text { HCA } \\
(\mathbf{N}=\mathbf{2 3})\end{array}$ & $\begin{array}{c}\text { Group 3, CPB }+\mathbf{H C A}+\mathbf{S C P} \\
(\mathbf{N}=\mathbf{1 0})\end{array}$ & $P$ value \\
\hline Age $(y$, mean $\pm S D)$ & $54.7 \pm 11.6$ & $61.6 \pm 15.9$ & $57.3 \pm 15.9$ & $.25^{*}$ \\
\hline Education $(y$, mean $\pm \mathrm{SD})$ & $15.6 \pm 2.7$ & $14.6 \pm 2.5$ & $13.5 \pm 2.1$ & $.09 *$ \\
\hline Education > 12 y $(\%)$ & $71 \%$ & $65 \%$ & $40 \%$ & $.23 \dagger$ \\
\hline $\operatorname{Sex}(\%$ male $)$ & $79 \%$ & $74 \%$ & $40 \%$ & $.07 \dagger, \ddagger$ \\
\hline Stay (d, median and range) & $6(4-9)$ & $8(5-25)$ & $8(6-30)$ & $<.01 \S, \|$ \\
\hline $\begin{array}{l}\text { Postoperative testing ( } \mathrm{d} \text {, median } \\
\text { and range) }\end{array}$ & $39(22-233)$ & $50(15-132)$ & $48(31-66)$ & $.038 \S, \|$ \\
\hline CPB time (min, median and range) $\Phi$ & $170(70-307)$ & $247(143-369)$ & $120.5(83-237)$ & $<.01 \S, \|$ \\
\hline HCA time (min, median and range)** & - & $21(14-31)$ & $30(14-40)$ & $.02 \S$ \\
\hline SCP time (min, median and range) & - & - & $68.5(39-83)$ & \\
\hline $\begin{array}{l}\text { Brain perfusion time (min, median } \\
\text { and range) } \dagger \dagger\end{array}$ & $170(70-307)$ & $247(143-369)$ & $198(128-284)$ & $.01 \S, \|$ \\
\hline $\begin{array}{l}\text { CPB onset-to-offset time (min, } \\
\text { median and range) } \ddagger \ddagger\end{array}$ & $170(70-307)$ & $270(171-390)$ & $232(162-309)$ & $<.01 \ddagger, \S, \|$ \\
\hline $\begin{array}{l}\text { Surgical time (min, median and } \\
\text { range) } \S \S\end{array}$ & $320(194-451)$ & $443(329-713)$ & $494(401-660)$ & $<.01 \ddagger, \S, \|$ \\
\hline
\end{tabular}


TABLE 3. Raw preoperative and postoperative neurocognitive test scores and $z$ score differences by group

\begin{tabular}{|c|c|c|c|c|}
\hline Test & $\begin{array}{l}\text { Group } 1 \text { CPB } \\
\text { only }(N=24)\end{array}$ & $\begin{array}{c}\text { Group } 2 \text { CPB }+ \text { HCA } \\
(\mathbf{N}=\mathbf{2 3})\end{array}$ & $\begin{array}{c}\text { Group } 3 \text { CPB }+ \text { HCA }+ \text { SCP } \\
(\mathbf{N}=10)\end{array}$ & $P$ value \\
\hline Digits Forward & & & & .870 \\
\hline Preoperative & $10.67 \pm 2.44$ & $9.26 \pm 2.22$ & $9.60 \pm 2.07$ & \\
\hline Postoperative & $10.83 \pm 2.75$ & $9.57 \pm 1.95$ & $9.60 \pm 1.78$ & \\
\hline Difference in $z$ score & $0.08 \pm 0.75$ & $0.14 \pm 0.80$ & $0.00 \pm 0.65$ & \\
\hline Digits Backward & & & & .397 \\
\hline Preoperative & $7.25 \pm 2.88$ & $6.04 \pm 1.69$ & $6.10 \pm 2.77$ & \\
\hline Postoperative & $7.46 \pm 3.11$ & $6.04 \pm 1.92$ & $5.50 \pm 2.64$ & \\
\hline Difference in $z$ score & $0.08 \pm 0.65$ & $0.00 \pm 0.64$ & $-0.22 \pm 0.56$ & \\
\hline Digit Span & & & & .343 \\
\hline Preoperative & $17.92 \pm 4.97$ & $15.30 \pm 3.48$ & $15.70 \pm 4.55$ & \\
\hline Postoperative & $18.29 \pm 5.46$ & $15.61 \pm 3.31$ & $15.10 \pm 3.84$ & \\
\hline Difference in $z$ score & $0.09 \pm 0.64$ & $0.07 \pm 0.52$ & $-0.14 \pm 0.38$ & \\
\hline TMT-A* & & & & .388 \\
\hline Preoperative & $24.50(21-30)$ & $32(25-41)$ & $31.5(29-37)$ & \\
\hline Postoperative & $25.0(21-30)$ & $30(27-49)$ & $32.0(21-39)$ & \\
\hline Difference in $z$ score & $0.00(-0.40$ to 0.32$)$ & $-0.27(-0.55$ to 0.12$)$ & $-0.14(-0.60$ to 0.18$)$ & \\
\hline TMT-B* & & & & $.032 \dagger, \ddagger, \S$ \\
\hline Preoperative & $58(47-78)$ & $85(68-142)$ & $86(59-86)$ & \\
\hline Postoperative & $60(40-72)$ & $88(51-107)$ & $91.5(56-163)$ & \\
\hline Difference in $z$ score & $0.14(-0.11$ to 0.38$)$ & $0.20(-0.21$ to 0.65$)$ & $-0.19(-0.41$ to 0.03$)$ & \\
\hline SDMT & & & & .482 \\
\hline Preoperative & $48.83 \pm 12.12$ & $46.05 \pm 10.78$ & $44.89 \pm 8.95$ & \\
\hline Postoperative & $51.71 \pm 14.07$ & $46.21 \pm 13.19$ & $44.80 \pm 8.82$ & \\
\hline Difference in $z$ score & $0.22 \pm 0.7$ & $0.01 \pm 0.49$ & $0.02 \pm 0.30$ & \\
\hline BNT-15 & & & & .172 \\
\hline Preoperative & $13.43 \pm 2.02$ & $13.09 \pm 1.50$ & $13.80 \pm 1.03$ & \\
\hline Postoperative & $13.78 \pm 1.62$ & $13.83 \pm 1.47$ & $13.60 \pm 1.17$ & \\
\hline Difference in $z$ score & $0.17 \pm 0.66$ & $0.35 \pm 0.50$ & $-0.09 \pm 0.70$ & \\
\hline HVLT-R Total Recall & & & & $.024 \|, \boldsymbol{\oplus}$ \\
\hline Preoperative & $22.83 \pm 4.80$ & $19.83 \pm 4.51$ & $22.20 \pm 6.07$ & \\
\hline Postoperative & $22.67 \pm 4.48$ & $21.61 \pm 5.80$ & $19.10 \pm 5.17$ & \\
\hline Difference in $z$ score & $-0.03 \pm 0.83$ & $0.35 \pm 0.81$ & $-0.61 \pm 0.98$ & \\
\hline HVLT-R Delayed Recall & & & & .931 \\
\hline Preoperative & $7.75 \pm 2.80$ & $6.87 \pm 2.42$ & $7.90 \pm 2.28$ & \\
\hline Postoperative & $7.83 \pm 2.12$ & $7.00 \pm 2.63$ & $7.60 \pm 5.38$ & \\
\hline Difference in $z$ score & $-0.02 \pm 0.85$ & $0.05 \pm 0.87$ & $-0.11 \pm 1.34$ & \\
\hline HVLT-R Retention & & & & .666 \\
\hline Preoperative & $87.38 \pm 17.58$ & $83.28 \pm 21.05$ & $111.63 \pm 51.25$ & \\
\hline Postoperative & $86.89 \pm 15.44$ & $83.67 \pm 24.42$ & $90.14 \pm 37.71$ & \\
\hline Difference in $z$ score & $0.00 \pm 0.48$ & $-0.01 \pm 0.71$ & $-0.45 \pm 1.28$ & \\
\hline HVLT-R Recognition & & & & .388 \\
\hline Preoperative & $10.00 \pm 1.91$ & $10.39 \pm 1.23$ & $9.80 \pm 1.48$ & \\
\hline Postoperative & $10.42 \pm 1.50$ & $10.09 \pm 2.37$ & $10.50 \pm 2.17$ & \\
\hline Difference in $z$ score & $0.20 \pm 0.79$ & $-0.15 \pm 1.23$ & $0.34 \pm 0.85$ & \\
\hline Stroop & & & & .799 \\
\hline Preoperative & $-1.35 \pm 5.51$ & $-2.14 \pm 4.89$ & $-3.25 \pm 6.66$ & \\
\hline Postoperative & $-1.38 \pm 6.73$ & $-0.75 \pm 5.57$ & $-2.85 \pm 6.52$ & \\
\hline Difference in $z$ score & $0.00 \pm 0.70$ & $0.14 \pm 0.71$ & $0.05 \pm 0.66$ & \\
\hline FTT & & & & $.019 \ddagger, \S, \|$ \\
\hline Preoperative & $49.76 \pm 10.12$ & $46.19 \pm 12.75$ & $45.70 \pm 13.21$ & \\
\hline Postoperative & $50.18 \pm 12.04$ & $44.64 \pm 12.47$ & $42.20 \pm 13.41$ & \\
\hline Difference in $z$ score & $0.15 \pm 0.33$ & $-0.12 \pm 1.03$ & $-0.32 \pm 0.63$ & \\
\hline
\end{tabular}


TABLE 3. Continued

\begin{tabular}{|c|c|c|c|c|}
\hline Test & $\begin{array}{l}\text { Group } 1 \text { CPB } \\
\text { only }(N=24) \\
\end{array}$ & $\begin{array}{c}\text { Group } 2 \text { CPB }+ \text { HCA } \\
(\mathbf{N}=\mathbf{2 3})\end{array}$ & $\begin{array}{c}\text { Group } 3 \text { CPB }+ \text { HCA }+ \text { SCP } \\
(\mathbf{N}=\mathbf{1 0}) \\
\end{array}$ & $P$ value \\
\hline GPB* & & & & .499 \\
\hline Preoperative & $69(66-77)$ & $83.5(74-101)$ & $79(72-88)$ & \\
\hline Postoperative & $69(63-76)$ & $80.5(74-116)$ & $75(63-105)$ & \\
\hline Difference in $z$ score & $0.24(-0.19$ to 0.61$)$ & $-0.13(-0.35$ to 0.55$)$ & $-0.28(-0.45$ to 0.38$)$ & \\
\hline
\end{tabular}

Tests are as listed in Table 1. CPB, Cardiopulmonary bypass; $H C A$, hypothermic cardiac arrest; $S C P$, selective cerebral perfusion. For normally distributed test scores, mean \pm SD is given. For nonnormally distributed test scores (TMT-A, TMT-B, and GPB), median with interquartile range is given. *For TMT-A, TMT-B, and GPB, the signs are reversed from the original scales, to reflect that longer time is associated with greater decline in cognitive function. $\dagger P$ value obtained with Wilcoxon/Kruskal-Wallis Test. $\ddagger$ The selective cerebral perfusion group differed significantly from the cardiopulmonary bypass group $(P<.05)$. $\S$ The selective cerebral perfusion group differed significantly from the hypothermic circulatory arrest group $(P<.05)$. $\| P$ value obtained with analysis of variance. $\uparrow$ The hypothermic circulatory arrest group differed significantly from the cardiopulmonary bypass group $(P<.05)$.

were statistically significant. Multiple regression analyses showed no statistically significant relationships between SCP time and the other domain scores; however, the correlations between SCP time and Attention, Executive Function, and Motor Function domain scores were negative and in the range of -0.3 to -0.5 , which is considered to be of moderate size for data of this nature.

\section{DISCUSSION}

This study examined neurocognitive function prospectively in cardiac and thoracic aortic surgical patients who underwent procedures with $\mathrm{CPB}$ alone, $\mathrm{CPB}$ plus HCA, or CPB plus HCA and SCP. In group comparison analyses, we found that patients who underwent procedures with SCP had significantly greater declines on 3 of 14 test scores. Multiple regression analyses revealed that SCP duration (range, 39-83 minutes) was a significant predictor of decline in performance on Memory and Language domain tests. HCA duration (range, 14-40 minutes) was unrelated to neurocognitive decline across all patients who underwent HCA (independent of group assignment). CPB duration (range, 70-369 minutes) across the entire sample of patients (independent of group assignment) was also unrelated to neurocognitive decline.

Other neurocognitive outcome studies have reported mixed results in patients undergoing thoracic aortic procedures with SCP. A study of 22 patients who underwent aortic arch repair with SCP at moderate hypothermia $\left(26^{\circ} \mathrm{C}\right)$ found no significant declines in test scores. ${ }^{15}$ Svensson and colleagues ${ }^{11}$ compared neurocognitive outcomes in 30 aortic arch surgical patients cooled to less than $20^{\circ} \mathrm{C}$ and randomly assigned to HCA, HCA plus RCP, or HCA plus $\mathrm{SCP}$ and found that mean postoperative test scores were significantly worse in the SCP group than in the HCA group. A study performed by Pacini and colleagues ${ }^{16}$ compared 16 patients who underwent aortic arch surgery with SCP with 14 patients who underwent elective CABG. They found no significant neurocognitive test score differences between the 2 groups or within the SCP group across 3 evaluations (preoperative, 1 postoperative week, and 6 postoperative months). By means of diffusion-weighted magnetic resonance imaging, they found that SCP was associated with diffuse vasogenic cerebral edema at 1 postoperative week and that this effect persisted in the temporal lobe at 6 postoperative months. This finding is notable because it is consistent with our finding of decline in performance on Memory and Language domain tests, because neurocognitive profiles characterized by episodic memory and language deficits against a background of otherwise normal cognitive function implicate temporal lobe pathology.

Our finding that HCA duration (range, 14-40 minutes) was unrelated to neurocognitive decline contrasts with our previous findings, in which prolonged HCA durations ( $\geq 25$ minutes) were associated with declines in memory and fine motor function. ${ }^{8}$ Our institutional approach to brain protection has evolved significantly since our 1999 publication, in that HCA periods overall became much shorter as SCP was introduced into clinical practice.

TABLE 4. Multiple regression analyses of the relationships of cardiopulmonary bypass, hypothermic cardiopulmonary bypass, and selective cerebral perfusion times with neurocognitive domain scores, adjusting for potential confounders

\begin{tabular}{|c|c|c|c|c|c|c|c|c|c|c|c|c|}
\hline \multirow[b]{2}{*}{ Outcome measure } & \multicolumn{3}{|c|}{ CPB time } & \multicolumn{3}{|c|}{ HCA time } & \multicolumn{3}{|c|}{ SCP time } & \multicolumn{3}{|c|}{ SCP time (propensity score analysis) } \\
\hline & $\beta^{*}$ & SE* & $P$ value & $\beta^{*}$ & $\mathrm{SE}^{*}$ & $P$ value & $\beta^{*}$ & $\mathrm{SE}^{*}$ & $P$ value & $\beta^{*}$ & $\mathrm{SE}^{*}$ & $P$ value \\
\hline Attention & 0.0009 & 0.0012 & .467 & -0.0140 & 0.0156 & .373 & -0.0070 & 0.0105 & .509 & -0.0089 & 0.0094 & .360 \\
\hline Speed & 0.0014 & 0.0010 & .166 & 0.0056 & 0.0133 & .674 & 0.0090 & 0.0092 & .335 & 0.0117 & 0.0103 & .274 \\
\hline Language & 0.0010 & 0.0012 & .392 & 0.0018 & 0.0150 & .232 & -0.0277 & 0.0105 & .011 & -0.0356 & 0.0092 & .002 \\
\hline Memory & -0.0008 & 0.0013 & .530 & -0.0132 & 0.0165 & .427 & -0.0349 & 0.0115 & .004 & -0.0274 & 0.0137 & .063 \\
\hline Executive & 0.0001 & 0.0017 & .959 & 0.0101 & 0.0215 & .640 & -0.0093 & 0.0142 & .516 & -0.0096 & 0.0150 & .534 \\
\hline Motor & 0.0022 & 0.0012 & .063 & 0.0178 & 0.0156 & .261 & -0.0061 & 0.0117 & .604 & -0.0185 & 0.0103 & .096 \\
\hline
\end{tabular}

*The $\beta$ coefficient and its SE were derived from linear regression model. 

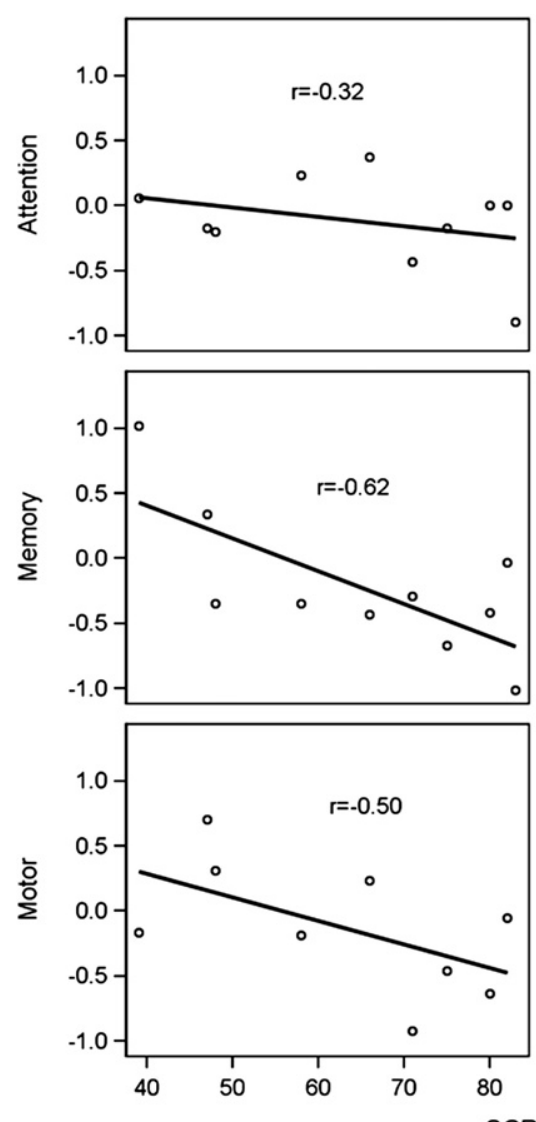

SCP Time (min)
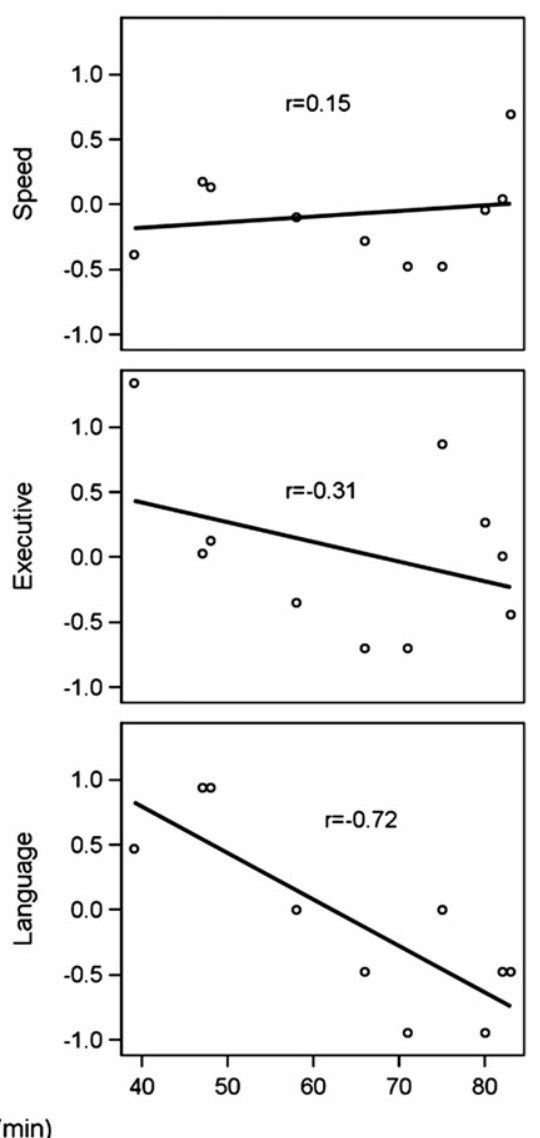

FIGURE 1. The relationships between selective cerebral perfusion (SCP) duration and neurocognitive domain scores (differences in $z$ scores), with Pearson correlation coefficients.

The nature of complex aortic repairs is that they are performed in referral centers, drawing patients from large geographic regions. This poses significant obstacles to neurocognitive outcomes research because, after hospital discharge, many patients are physically inaccessible for follow-up testing, resulting in high attrition. Those patients who do return to the center after hospital discharge typically are only available for postoperative neurocognitive testing on the day that they are scheduled for follow-up with their surgeons. We believe that such limitations are common in long-term neuropsychologic testing studies of surgical patients at referral centers. Furthermore, it is impractical to generalize findings across small studies from multiple centers or to perform meta-analytic studies because of variations in the ways that HCA, RCP, and SCP are practiced and also in the methods of neurocognitive evaluation.

Although it is reasonable to expect poorer neurocognitive outcomes in patients undergoing extensive reconstructive surgery of the aortic arch requiring SCP, the findings of this study are limited by the small postoperative sample size and the wide variation in timing of postoperative testing. Despite the small sample size, however, the propensity score analysis did confirm the association between SCP duration and decline in Language domain (naming) test scores. A similar trend of an effect of SCP on decline in Memory domain scores did not retain statistical significance $(P=.06)$, however, and the findings regarding memory decline thus should be considered less definitive. We also acknowledge that the number of covariates collected in this study is limited. For example, ranges of hemoglobin concentration, perfusion pressures, and flow rates during CPB and SCP were not investigated. Despite these limitations, the traditional regression analysis and the confirmatory propensity score analysis were concordant. These data indicate that future investigations with larger patient samples and more covariates are warranted.

Neurocognitive outcome studies are essential in evaluating the efficacy of neuroprotection strategies for thoracic aortic surgery. We present these preliminary data to demonstrate that SCP did not eliminate the neurocognitive decline that has been previously identified as a problem in complex aortic arch repairs. Prospective multicenter investigation that uses remote, Internet-based neurocognitive testing, with uniform test selection and test timing, is the most promising approach for such studies. We have previously demonstrated that studying neurocognitive 
outcomes with such technology is practical in this patient population. ${ }^{17}$

In conclusion, our institution changed its clinical approach to brain protection in complex aortic repairs nearly 15 years ago in response to our clinical and laboratory findings that prolonged HCA was associated with deleterious cognitive outcomes. Our current data do not support the principle that substitution for prolonged HCA with shorter periods of HCA combined with SCP alleviates the problem of cognitive dysfunction after complex aortic arch repairs. Further research is required to validate these findings in larger clinical studies.

\section{References}

1. Griepp RB, Stinson EB, Hollingsworth JF, Buehler D. Prosthetic replacement of the aortic arch. J Thorac Cardiovasc Surg. 1975;70:1051-63.

2. Reich DL, Uysal S, Ergin MA, Griepp RB. Retrograde cerebral perfusion as a method of neuroprotection during thoracic aortic surgery. Ann Thorac Surg. 2001;72:1774-82.

3. Apostolakis E, Akinosoglou K. The methodologies of hypothermic circulatory arrest and of antegrade and retrograde cerebral perfusion for aortic arch surgery. Ann Thorac Cardiovasc Surg. 2008;14:138-48.

4. Gega A, Rizzo JA, Johnson MH, Tranquilli M, Farkas EA, Elefteriades JA. Straight deep hypothermic arrest: experience in 394 patients supports its effectiveness as a sole means of brain preservation. Ann Thorac Surg. 2007;84:759-67.

5. Bachet J. What is the best method for brain protection in surgery of the aortic arch? Selective antegrade cerebral perfusion. Cardiol Clin. 2010;28:389-401.

6. Elefteriades JA. What is the best method for brain protection in surgery of the aortic arch? Straight DHCA. Cardiol Clin. 2010;28:381-7.
7. Ueda Y. What is the best method for brain protection in surgery of the aortic arch? Retrograde cerebral perfusion. Cardiol Clin. 2010;28:371-9.

8. Reich DL, Uysal S, Sliwinski M, Ergin MA, Kahn RA, Konstadt SN, et al. Neuropsychologic outcome after deep hypothermic circulatory arrest in adults. $J$ Thorac Cardiovasc Surg. 1999;117:156-63.

9. Reich DL, Uysal S, Ergin MA, Bodian CA, Hossain S, Griepp RB. Retrograde cerebral perfusion during thoracic aortic surgery and late neuropsychological dysfunction. Eur J Cardiothorac Surg. 2001;19:594-600.

10. Harrington DK, Bonser M, Moss A, Heafield MT, Riddoch MJ, Bonser RS. Neuropsychometric outcome following aortic arch surgery: a prospective randomized trial of retrograde cerebral perfusion. J Thorac Cardiovasc Surg. 2003; 126:638-44.

11. Svensson LG, Nadolny EM, Penney DL, Jacobson J, Kimmel WA, Entrup MH, et al. Prospective randomized neurocognitive and S-100 study of hypothermic circulatory arrest, retrograde brain perfusion, and antegrade brain perfusion for aortic arch operations. Ann Thorac Surg. 2001;71:1905-12.

12. Etz CD, Homann TM, Rane N, Bodian CA, Di Luozzo G, Plestis KA, et al. Aortic root reconstruction with a bioprosthetic valved conduit: a consecutive series of 275 procedures. J Thorac Cardiovasc Surg. 2007;133:1455-63.

13. Spielvogel D, Etz CD, Silovitz D, Lansman SL, Griepp RB. Aortic arch replacement with a trifurcated graft. Ann Thorac Surg. 2007;83:S791-5; discussion S824-31.

14. Mack WJ, Freed DM, Williams BW, Henderson VW. Boston Naming Test: shortened versions for use in Alzheimer's disease. J Gerontol. 1992;47:154-8.

15. Özatik MA, Küçüker SA, Tülüce H, Sartiaş A, Sener E, Karakaş S, et al. Neurocognitive functions after aortic arch repair with right brachial artery perfusion. Ann Thorac Surg. 2004;78:591-5.

16. Pacini D, DiMarco L, Leone A, Tonon C, Pettinato C, Fonti C, et al. Cerebral functions and metabolism after antegrade selective cerebral perfusion in aortic arch surgery. Eur J Cardiothorac Surg. 2010;37:1322-31.

17. Uysal S, Mazzeffi M, Lin HM, Fischer GW, Griepp RB, Adams DH, et al. Internet-based assessment of postoperative neurocognitive function in cardiac and thoracic aortic surgery patients. J Thorac Cardiovasc Surg. 2011;141: $777-81$. 